\title{
Panamá: la supresión de las Fuerzas de Defensa
}

\author{
Gregorio Selser
}

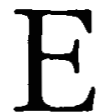

1 preanunciado objetivo de la supresión de las Fuerzas de Defensa de Panamá (FDP) tuvo un principio de materialización a partir de la invasión del país el 20 de diciembre de 1989 , ordenada por el presidente de Estados Unidos, George Bush. Para ello fue necesario el derrocamiento de las autoridades constituidas y su reemplazo por otras escogidas en Washington en las horas mismas en que se enfrentaban las tropas extranjeras y el ejército local respaldado por milicias civiles irregulares.

Una de las notas ominosas de ese proceso inicial intervencionista lo constituye el detalle de que los nuevos gobernantes juraron como tales ante funcionarios militares y diplomáticos estadunidenses, con total ausencia de personas jurídicas y constitucionales panameñas aptas para legitimar tan ilegal procedimiento. Peor aún, la abusiva ceremonia se realizó en dependencias de la base militar de Fort Clayton, territorio no revertido de la zona del canal y por lo tanto y a todos los efectos, de propiedad, jurisdicción y soberanía de Estados Unidos. Siete días más tarde, estas espurias autoridades recibieron una discutible convalidación de los miembros del Tribunal Electoral que, en mayo de 1989, habían resuelto anular los comicios generales. Así, siete meses después de haberlos cancelado, consagraban sus supuestos resultados como legales, con fundamento en documentación 
tan dudosa como la propia resolución rectificatoria.

La secuencia de sucesos, registrados por fuentes periodísticas no panameñas pero a las que habitualmente se consideran responsables y dignas de crédito y que escogemos precisamente porque se ubicaron a favor de la invasión, muestra que las operaciones bélicas estaban en pleno desarrollocuandolos políticosopositores Guillermo Endara Galimany, Ricardo Arias Calderón y Guillermo Ford fueron "citados por funcionarios de Estados Unidos al anochecer e informados de los planes militares en curso". ${ }^{1}$ El representante demócrata Les Aspin, de Wisconsin, titular de la Comisión de Servicios Armados de la Cámara de Representantes, declaró que "el presidente Endara fue, en esencia, instalado en su cargo por Estados Unidos".

Se lee, además, en el Post:

Endara prestó juramento como presidente en una base militar de Estados Unidos en (la zona del canal de) Panamá en una ceremonia que precedió escasamente al asalto de 24000 soldados norteamericanos realizado para derribar a Noriega. Muchos observadores coinciden en que Endara deberá superar el detalle de haber sido ubicado en el poder por Estados Unidos. Muchos panameños censuran a Endara por haber prestado juramento en un establecimiento militar estadunidense, y haber enviado uno de sus primeros documentos oficiales a la Organización de Estados Americanos (OEA), desde un telefax del cuartel general del Comando Sur del ejército de Estados Unidos. ${ }^{3}$

${ }^{1}$ Andrew Rosenthal, "US troops gain wide control in Panama", The New York Times, 21 de diciembre de 1989, pp. 1 y 18.

${ }^{2}$ R.W. Apple Jr., "Panama. Big obstacles to victory", The New York Times, 22 de diciembre de 1989, pp. 1 y 17.

${ }^{3} J u l i a$ Preston, "US installed president seeks to
Lo despreciaban incluso aquellos que estaban felices con la así llamada operación "Just Cause":

No existe hoy un gobierno en Panamá. Guillermo Endara, el aparente ganador de las abortadas elecciones de mayo pasado, carece de autoridad confiable, por haber sido instalado en su cargo en una base militar norteamericana en vísperas de la invasión. Su primera aparición ante la Asamblea Nacional panameña ayer, tuvo que estar custodiada por una poderosa guardia militar de Estados Unidos. ${ }^{4}$

Endara, con noción cabal del papel de títere impuesto que le adjudicaba incluso la prensa que respaldaba la intervención militar (The New York Times, The Washington Post, The Miami Herald, The Philadelphia Inquirer, entre otros periódicos), intentó una débil defensa, dando su propia versión de lo ocurrido:

La noticia de la invasión de Estados Unidos fue como un golpe en la cabeza. Yo pensé que no era lo mejor que podía hacerse. No fuimos realmente consultados. Yo hubiera sido másfeliz sin una intervención. Muy diplomáticamente se nos informó del plan del presidente Bush dos o tres horas antes de que éste fuera lanzado. Éste es un gobiemo dudoso. Me he hecho cargo del gobierno de un país invadido por otro país. Puedo trabajar con los norteamericanos. Los gringos tienen sus defectos, pero estoy acostumbrado a ellos. Niego haber prestado juramento ante un juez en una base militar de Estados Unidos. Yo juré en territorio panameño, en un edificio panameño después de la una de la madrugada. Recién por la mañana fuimos a (la base militar estadunidense de) Fort Clayton. $^{5}$

assert his rule", The Washington Post, 22 de diciembre de 1989, p. 35.

4 "Panama for the panamanians", editorial del New York Times, 22 de diciembre de 1989, p. 24.

"Eloy A. Aguilar, "Panama chiefs says US gave 


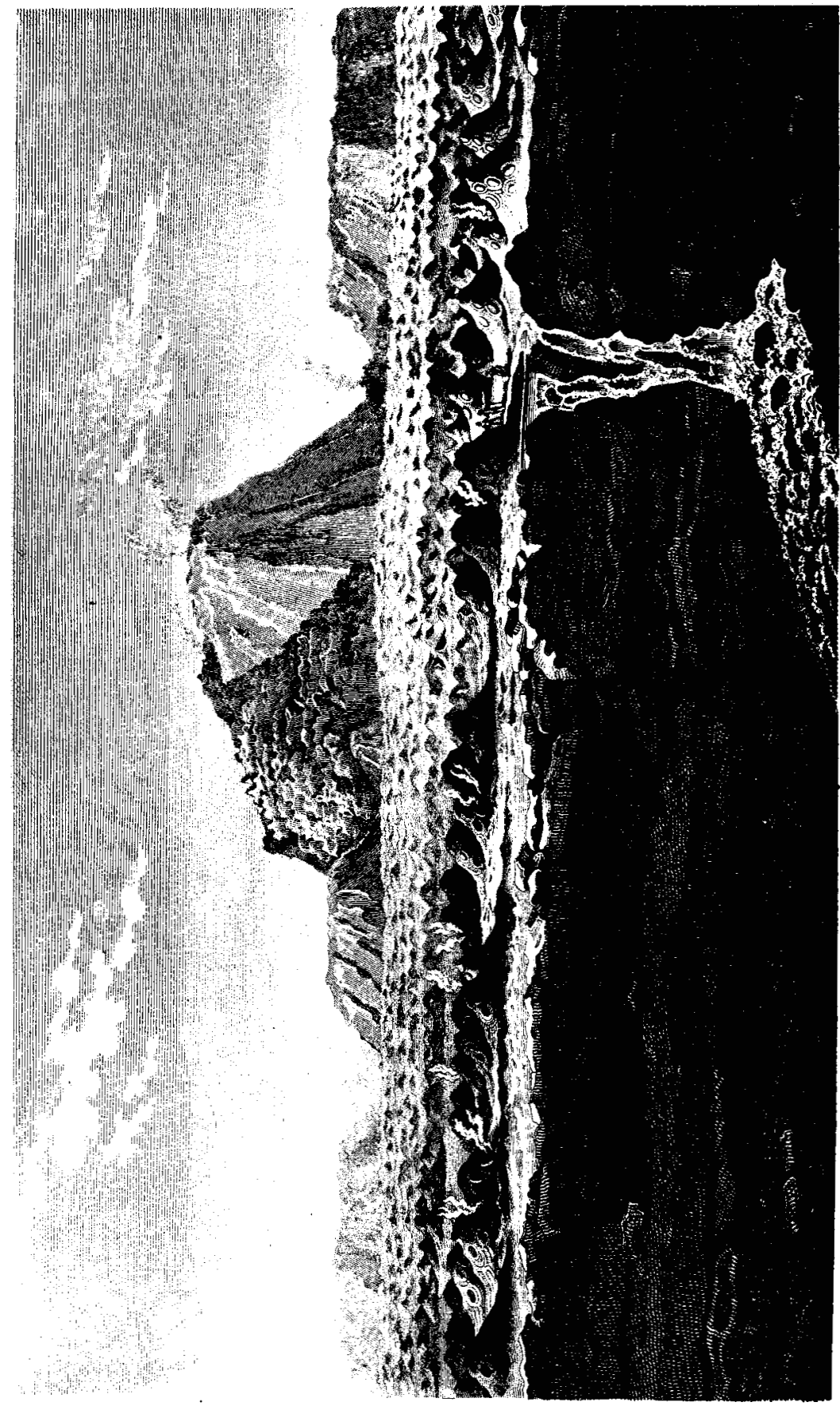


No era cierto y esa aseveración no iba a tardar en ser desmentida con detalles de tal naturaleza que, tanto él como sus hermanos en sumisión, Arias Calderón y Ford, ya no pudieron refutar. Cabe en tal sentido rescatar la versión que proveyó el Herald de Miami:

"Dos horas después de iniciada la invasión a Panamá el 20 de diciembre, el nuevo presidente panameño, sus dos vicepresidentes y dos testigos de esa inauguración realizada en una base militar estadunidense, concertaron un pacto secreto para relatar al mundo que ellos habían efectuado tal ceremonia en territorio panameño -reveló uno de los cinco participantes.

$x$ "Endara dijo que después de que él y los dos vicepresidentes juraron sus cargos en 'una casa panameña en territorio panameño' inmediatamente después de iniciarse la invasión, aproximadamente a la una del miércoles, fueron traslada dos por autoridades estadunidenses a Fort Clayton por razones de seguridad. Pero los cinco hombres que firmaron el texto del juramento de un párrafo, anticipándose a futuras preguntas acerca de la legitimidad desu gobiemo, juraron entre sí guardar el secreto acerca del lugar de la ceremonia.

"Se concertaron para decir públicamente que fueron llevados desde Fort Clayton a una casa en territorio panameño-dijo una fuente responsable que participó en el acuerdo y que pidió no ser identificada. El documento de juramentación fue firmado por Endara, Arias Calderón, Ford y los dirigentes de la Comisión Panameña de Derechos Humanos -Osvaldo Velázquez y José Manuel Faundes-, estos dos últimos por ausencia de un juez.

little waming", The Washington Post, 24 de diciembre de 1989 , p. 1.
"Estuvieron también presentes Teresa, esposa de Arias y Dorita, esposa de Ford, así como el encargado de negocios de Estados Unidos, John Bushnell, la funcionaria de la embajada Patricia Perry y varios oficiales militares norteamericanos. 'Fuimos llevados a Fort Clayton cerca de la medianoche y se nos recomendó que no hiciéramos llamadas telefónicas ni abandonáramos la habitación' -dijo uno de los participantes. 'La ceremonia se realizó cerca de las 2 am y acordamos que diríamos que aquélla tuvo lugar en territorio panameño.'

"El grupo permaneció en el edificio de Fort Clayton hasta la tarde del miércoles, cuando dos morteros de las fuerzas de Noriega estallaron a unas 200 yardas del lugar. Entonces fueron llevados a otra casa de Fort Clayton, donde permanecieron hasta la mañana del jueves, unas 30 horas después de iniciada la invasión. Entonces el trío fue llevado directamente desde Fort Clayton hasta el edificio de la Asamblea Legislativa de Panamá, donde las tropas de Estados Unidos establecieron la primera sede del gobierno provisional de Endara. ${ }^{n 6}$

En síntesis, que solamente hubo seis panameños en la clandestina ceremonia (la esposa de Arias Calderón es cubana) y el resto, según otras versiones periodísticas, ciudadanos civiles y militares estadunidenses en número no inferior a dos docenas. Nacidos, traídos y llevados por las tropas invasoras a desempeñar bajo tan ominoso paraguas un papel de secuaces de la intervención que iría a mantenerse durante los meses siguientes, tales tristes protagonistas necesitaron alguna forma de legitimación ante el mundo que resultara menos humillante.

\footnotetext{
${ }^{6}$ Andres Oppenheimer, "Participant: secret pact made over inaugural sit", The Miami Herald, 27 de diciembre de 1989 , p. 1.
} 
Endara, consciente de su deplorable función, necesitó justificarse ante un diario español. Después de mentir de nuevo en relación con la hora de su juramentación, expresó:

Cuando iniciamos el gobierno, Panamá ya estaba invadida. Consideramos la opción de no aceptar el gobierno que nos ofrecían. Nos dimos cuenta de que no podíamos rechazarlo, hubiera sido una gran irresponsabilidad. Alguien tenía que asumir el poder civil. Lo mejor era que lo hicieran las personas que el pueblo eligió. [...] No soy un títere, eso no es cierto. No soy manejado por nadie. Más que la opinión internacional, me preocupa la opinión nacional. Los panameños están con su presidente. El pueblo sabe que nadie me maneja. Ellos [los invasores] no influyen en las decisiones que se toman en este despacho. $^{7}$

El mismo día que se publicaban estas declaraciones, el dócil trío de Fort Clayton escenificaba ante la prensa local e internacional la ceremonia de su purificación "legal", en el edificio del Ministerio de Relaciones Exteriores de Panamá. Los miembros del Tribunal Electoral que, el 10 de mayo anterior, habían anulado las elecciones de 72 horas antes alegando numerosas irregularidades de variado tipo, ahora se corregían a sí mismos y daban validez a presuntos cómputos deducidos de supuestas copias de actas, no de los originales que al parecer habían sido destruidos, documentación de improbablesino imposible legitimidad y que, por si fuera poco, aquéllos admitían que no era completa. Los tres miembros del tribunal, Yolanda Pulice de Rodríguez -presidente-, Carlos Salinas Bonilla-secretario general-y

${ }^{7}$ Guillermo Endara, declaraciones a La Vanguardia, 27 de diciembre de 1989, Barcelona.
Luis Chen, convalidaron la nueva superchería ante un Endara por primera vez investido con la banda presidencial. "Tras evaluar las actas con los resultados que obraban en poder de la sede de la Curia Metropolitana, fue posible reconocer el resultado de las elecciones... y anular en consecuencia el decreto", dijo la Pulice al entregar a Endara y los dos vicepresidentes de facto los singulares documentos.

La magistrada se había refugiado en una embajada extranjera en cuanto se produjo la invasión. Salió de ella en cuanto recibiô seguridades -avaladas por los invasores- de que no sería procesada ni recluida en prisión a raíz de aquella resolución de mayo. A cambio y por no existir otras autoridades del Tribunal Electoral, ella y sus adjuntos debían rectificarse... y de paso purificarse, y así lo aceptaron. Tal era la versión que recogió la prensa internacional. El enviado especial de una publicación californiana que se edita en español publicó esta reseña testimonial de lo que vio y oyó:

Guillermo Endara fue declarado hoy ganador de las elecciones presidenciales del pasado 7 de mayo, las que fueron anuladas por el mismo tribunal electoral que hoy declaró su triunfo. Dicha anulación ha sido una de las justificaciones que la administración Bush dio para la invasión militar a Panamá. La presidenta del tribunal entregó a Endara las credenciales correspondientes, en una tumultuosa ceremonia en la que no se permitió que la magistrada respondiera a preguntas de la prensa.

La mujer estaba pálida y no atinó a decir una sola palabra ante los gritos y acosos de los reporteros que preguntaban si había sido obligada a firmar el decreto del "triunfo" de Endara. Fue retirada del lugar por funcionarios del nuevo gobierno en acto parecido a cuando la autoridad policial se lleva preso a alguien. "No ha 
habido ningún tipo de compromiso, fue una acción voluntaria" -respondió Endara por la magistrada. "Fue un acto de alto patriotismo, se rectificaron errores -agregó-es el inicio de una era de democracia."

Según las cifras del Tribunal Electoral, la coalición de Endara ganó la elección de mayo con $62 \%$ de los votos, contra 24 que consiguieron las fuerzas aliadas con el general Noriega. En mayo el tribunal anuló la elección argumentando que debido al cúmulo de irregularidades, era imposible determinar el resultado del proceso. Hoy, en cambio, se explicó que gracias a las copias de las actas del escrutinio que facilitó la nunciatura vaticana, se pudo acreditar el triunfo de Endara. Estas actas, a su vez, fueron proporcionadas a la Iglesia católica por el mismo partido de Endara. ${ }^{8}$

${ }^{8}$ Carlos Ramos, "Declaran triunfador a Endara", La Opinión, 28 de diciembre de 1989, Los Ángeles, p. 1.
Otro testigo de la farsa, procedente de España, agregó nuevos detalles ilustrativos:

Los mismos miembros del Tribunal Electoral que anuló las elecciones del 7 de mayo, declararon y ratificaron oficialmente la victoria de Endara como presidente. La propia titular de aquel tribunal, Yolanda Pulice de Rodriguez, que fue insultada por el público, permaneció sentada ante los periodistas, con cara de no haber roto un plato en su vida. La misma que ratificó y ordenó la anulación de las elecciones, mediante el surrealista decreto 58 [...] afirma ahora que aquello fue un lamentable error. Asî es Panamá. Los resultados definitivos quefueron suministrados arrojan el siguiente resultado: 473838 votos para el partido de Endara ( $62 \%$ del total de papeletas); 188714 para COLINA, de Noriega (24.9) y 2822 para el Partido Panameñista $(0.4 \%)$. Los votos en blanco fue-

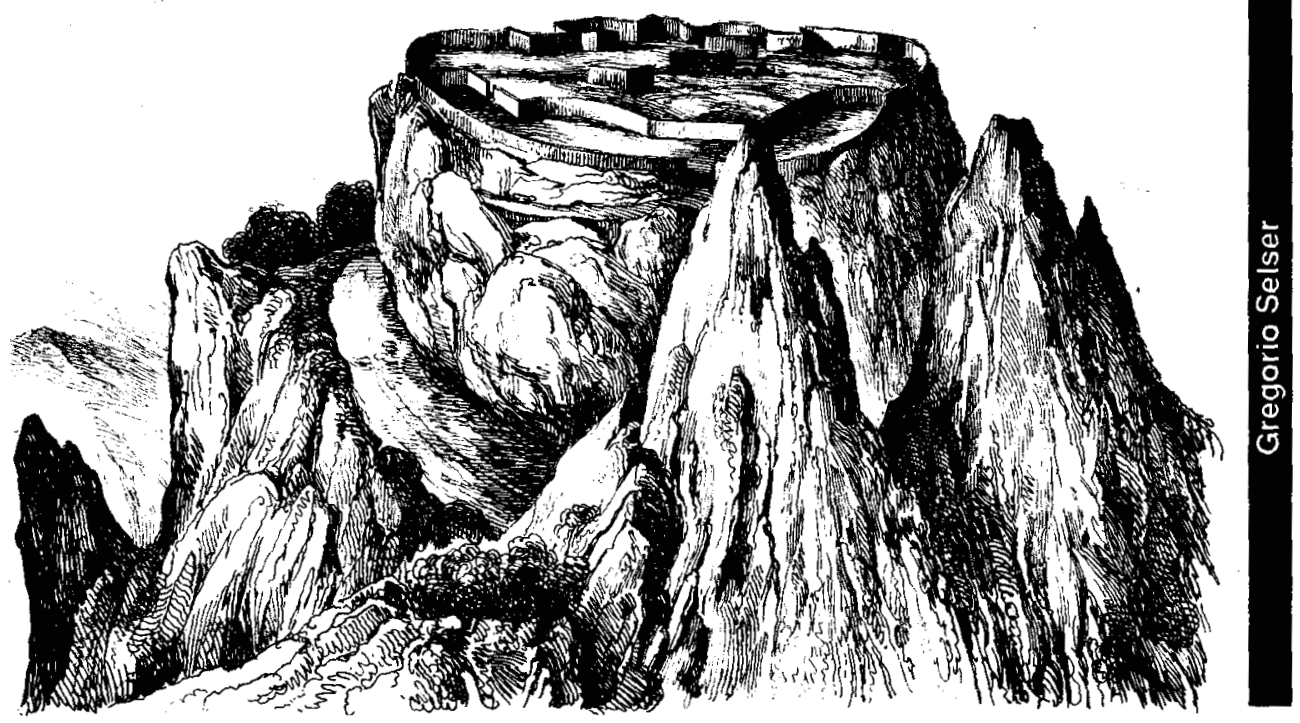


ron 22 243, se escrutaron 3536 mesas y 769 no fueron escrutadas. En total 757797 votos. ${ }^{9}$

Según la reseña de un diario mexicano, ese número de votos correspondía a $83.1 \%$ del total de votantes:

Las 719 actas del $16.9 \%$ restante desaparecieron aquella noche. A pesar del acoso de los grupos paramilitares norieguistas, los miembros de ADO-Civilista en las casillas electorales lograron conservar copias de las actas con los resultados y las depositaron en la Curia poco después de los comicios. Pulice, quien personalmente anunció la anulación de los comicios poco antes de la medianoche del 10 de mayo, agradeció hoy a ese partido por haber rescatado los documentos. ${ }^{10}$

Si, como anotó el enviado de El Mundo, "así es Panamá", correspondería reproducir el texto mediante el cual Pulice anuló aquellas elecciones:

"Considerando que el Tribunal Electoral convocó al pueblo a elecciones populares a celebrarse el 7 de mayo de 1989, con el objeto de elegir presidente y vicepresidente de la república, legisladores, representantes y concejales.

"Que estas elecciones fueron organizadas en medio de la más aguda crisis fiscal y económica que sufre la república de Panamá, con el ánimo de brindar al pueblopanameñola oportunidad de producir la renovación de sus principales órganos de gobierno dentro de la legalidad y para demostrar al mundo la voluntad de actuar dentro del marco de la de-

9 Julio Fuentes, "Endara critica a la Nunciatura Apostólica", El Mundo, 28 de diciembre de 1989, Madrid, p. 7.

10 José Meléndez y Marta Anaya, "Proclaman a Endara vencedor de los comicios de mayo", Excélsior, 28 de diciembre de 1989, México, pp. 1 y 27. mocracia, a pesar de que el ejercicio electoral significó un enorme sacrificio económico y una distracción de esfuerzos ante los constantes ataques del agresor.

"Que terminadas las votaciones a las cinco de la tarde se produjeron hechos que aún persisten y los cuales han alterado de manera significativa el resultado final de las elecciones en todo el pais.

"Que el desarrollo normal de las elecciones fue altera do por la acción obstruccionista de muchos extranjeros llamados por las fuerzas políticas nacionales o foráneas, sin gozar de una invitación del Tribunal Electoral, y cuyo evidente y único propósito era el de avalar la tesis del fraude electoral proclamada al mundo por las autoridades norteamericanas desde fecha muy anterior a las elecciones.

"Que la relación sucinta de estos hechos, según se desprende de los informes recibidos por el Tribunal Electoral de los coordinadores, inspectores electorales y funcionarios responsables dela Dirección General de Organización Electoral, asi como de las juntas escrutadoras y proclamadoras, da cuenta de la constante sustracción de las boletas en los recintos electorales, compra de votos por los partidos políticos y, especialmente, la falta de actas y otros documentos que hacen absolutamente imposible la proclamación de cualquiera de los candidatos que, de conformidad con el artículo 136 de la Constitución Política y los artículos 290 y 291 del Código Electoral, el Tribunal Electoral podrá declarar de oficio la nulidad de las elecciones.

"Que todas y cada una de las anteriores consideraciones conducen a este Tribunal a concluir, en vista de todos los hechos y las circunstancias anotadas, que la medida adoptada contribuirá a devolver la tranquilidad al país y proteger la vida 
y bienes de todos los habitantes del territorio nacional. Y decreta:

"1. Se declara la nulidad delas elecciones celebradas el 7 de mayo de 1989, en su totalidad, en todos los niveles de todos los cargos de elección popular previstos para ser proclamados en las mismas.

"2. Se ordena enviar a todos los órganos del Estado, ejecutivo, legislativo y judicial, copia del informe a que se refiere lo aquí dispuesto, a fin de que se promuevan las medidas constitucionales y legales tendientes a preservar el orden constitucional y legal de la república."

De modo que Pulice pasó por alto todos los argumentos que ella misma había considerado pertinentes para anular las elecciones, entre ellos "la falta de actas y otros documentos" y, siete meses después, aceptó como legales "copias" -y no todas, pues faltaron 719 que quizás habrian podido proveer cifras no tan $\mathrm{fa}$ vorables a Endara- y por añadidura agradeció a la $A D O C$ y a la Curia por su rescate. Tan egregia magistrada no tardó en ser recompensada: semanas más tarde y por pedido oficial era designada miembro de la Corte Suprema de Justicia.

DE FUERZAS DE DEFENSA A POLICIA "DE PITO Y TOLETE"

En la guerra de propaganda y acción sicológica desatada por Estados Unidos con el propósito de preparar a la opinión pública interna e internacional y predisponerla a su favor de cara a la intervención que fraguaba, dos de las razones más importantes fueron meticulosamente sustraídas al conocimiento general: 1) la voluntad de Washington -que comenzó a insinuarse a partir de 198485-de prolongar su permanencia militar en la zona del canal más allá del 31 de diciem-bre de 1999 y contrariando lo con- venido en los Tratados Torrijos-Carter; y 2) su objetivo de modificar sustancialmente la estructura de las Fuerzas de Defensa de Panamá (FDP), cuya oficialidad estaba en su mayor parte identificada con el ideario torrijista de recuperar para el Estado y el pueblo panameños ese territorio irredento.

Tan buen éxito tuvo en ese ocultamiento de propósitos, que estudiosos tan analíticos y penetrantes como James Petras y Noam Chomsky, que entre los norteamericanos fueron de los primeros en destacar la falsedad de la argumentación justificatoria intervencionista del presidente Bush, pasaron por alto esos dos motivos fundamentales. ${ }^{11}$ Desde este lado del río Bravo, empero, fueron abundantes los señalamientos de esos fines primordiales de la estrategia puesta en práctica, tanto en el propio Panamá como en otros países del hemisferio. No fue por azar que el 10 de mayo de 1989 , día de la anulación de las elecciones, un cable de la agencia española EFE desde Panamá informara que el teniente coronel Daniel Delgado Diamante había denunciado que el presidente venezolano Carlos Andrés Pérez -pieza activa de primer nivel en el plan desestabilizador de Bush-presentó a tres militares de las FDPuna propuesta para que destituyeran al general Manuel A. Noriega, se ubicara en su lugar una junta militar de gobierno provisional y que, después de ello, se convocara a nuevas elecciones.

Tal propuesta había sido transmitida por el ciudadano colombiano Carlos Pérez Narsogaray al agregado militar de la embajada de Panamá en Bogotá, ca-

\footnotetext{
"Véase a este respecto James Petras, "Ocho mitos y una realidad", Brecba, 9 de febrero de 1990, Montevideo, pp. 15-18, y Noam Chomsky, "The tasks ahead IV: post-cold war", Zeta Magazine, march, 1990, Boston, pp. 8-18.
} 


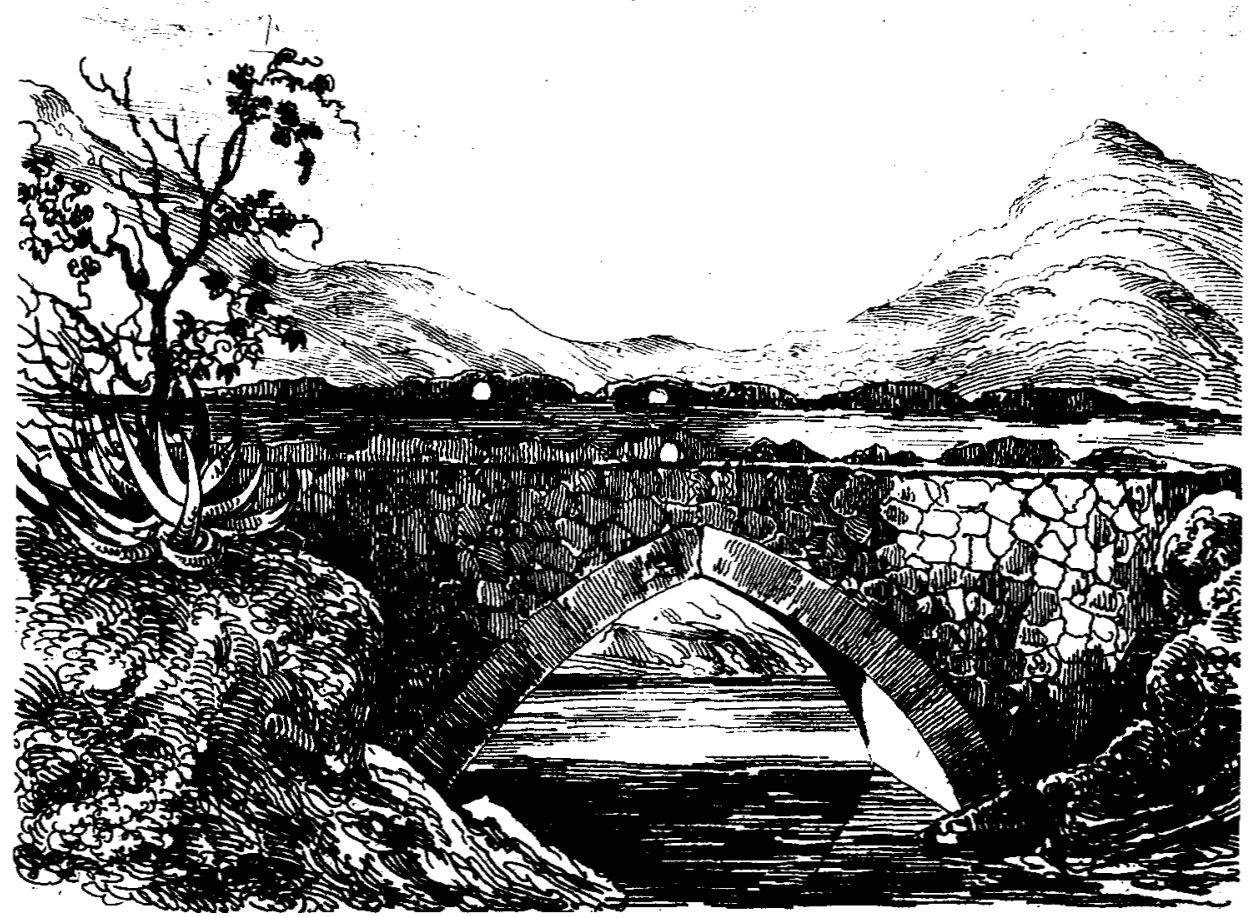

pitán Marcos Arjona. Estaba dirigida al coronel Guillermo Wong, jefe del G-2 (Inteligencia Militar), al teniente coronel Carlos Arosamena y al propio Delgado Diamante. Los tres debían arrestar a Noriega, anular las elecciones, instalar un régimen provisional integrado por "tres figuras públicas vinculadas al torrijismo", con exclusión de Guillermo Endara, Ricardo Arias Calderón y Guillermo Ford "por su compromiso con los norteamericanos y falta de credibilidad ante la comunidad latinoamericana". La junta debía reformar a las FDP, disolver su estado mayor y suprimir el cargo de comandante. Pérez ofrecía a cambio una ayuda económica inmediata, obtener el reconocimiento internacional de la junta y la reintegración de Panamá al Grupo de los Ocho.
Resultaba sugestivo que entre los tres a los que se incitaba a la sedición figurara Delgado Diamante, el militar que había estado denunciando permanentemente ante sus camaradas la naturaleza real de la operación desestabilizadora iniciada por el presidente Ronald Reagan, a saber, la voluntad de Washington de retener, más allá del año 2000, al menos cuatro instalaciones militares básicas. En marzo de 1988 él mismo proporcionó esa clave de la agresión:

"¿Por qué se produce precisamente ahora esa ofensiva contra Panamá? Porque para que Estados Unidos cumpla con los tratados y el 31 de diciembre de 1999 salgan de nuestro territorio sus últimos soldados, requiere de un programa de desmantelamiento de bases y el retiro de fuerzas que le tomaría diez 
años reubicar. No es que lo diga yo. Los estudios hechos por el Departamento de Defensa demuestran que el proceso de salida y de reemplazamiento de sus fuerzas convencionales, requiere que desde ahora o a más tardar en 1989 se inicie el cambio. Pero si Panamá les niega el beneplácito para que permanezcan más allá del año 2000, es claro que necesitan panameños que traicionen la causa de la liberación nacional y les concedan esa permanencia a como dé lugar y cuanto antes.

"Es claro que saben del valor estratégico del canal, de sus bases e instalaciones. Una de ellas, la mayor del continente americano desde las fronteras de México hasta el confin austral, está en nuestro país. Es el centro de inteligencia y de comunicaciones electrónicas más grande del mundo, en una isla que ninguno de los negociadores tomó en cuenta cuando se firmaron los Tratados Torrijos-Carter: la isla de Galeta, cerca de Colón, en el Atlántico, también llamada 'Isla de las Antenas', donde se ubica el corazón de la inteligencia electrónica de Estados Unidos, incluyendo la de las comunicaciones espaciales y las de los submarinos nucleares.

"En la base aérea Howard, la más grande en su tipo en el hemisferio, pueden recibirse todos los sistemas aéreos más sofisticados con que cuenta la fuerza aérea norteamericana. Ya no la quieren entregar; y tampoco Fort Sherman, donde está la Escuela de Supervivencia en la Selva; allí se entrenan sus soldados como parte de su preparación para el combate en los conflictos de baja intensidad y en escenarios bélicos del Tercer Mundo. Ahí se están realizando ahora las maniobras Total Warrior que el pueblo y el gobierno panameños no han autorizado.

"Igualmente Fort Clayton, donde está ubicada la fuerza de tierra de Estados Unidos, su Brigada de Infantería 193 y donde se pretende ubicar el Comando Sur, eje funcional de la estrategia militar de Estados Unidos para el hemisferio. El Comando Sur está en Panamá por la fuerza, ilegalmente, de hecho. Aunque no fue pactado en los Tratados TorrijosCarter -donde ni siquiera es mencionado-hoy es el centro desde el cual se manejan, se controlan, se supervisan, se coordinan las operaciones en todo el continente, a la luz de la estrategia militar de Estados Unidos. Fundamentalmente es 'todo eso' lo que quieren renetener. Pero como los tratados dicen otra cosa y las FDP tutelan su cabal cumplimiento, se entiende que quieran cambiar la letra y el espíritu de los tratados y de paso exterminar ese obstáculo en el menor plazo posible." ${ }^{12}$

En la misma dirección aunque desde otro enfoque, apuntó el sociólogo mexicano Marco A. Gandásegui, conocido crítico de los militares:

No es casual que Estados Unidos inicie su ofensiva contra Panamá en 1986. En sus cálculos, el gobierno panameño no tiene una base social y sus principales personeros no responden a intereses capaces de enfrentarse a Estados Unidos. Liquidando el torrijismo, Washington consideraba que una acción contra Panamá sería rápida y eficaz (a lo Granada).

La Casa Blanca se encontró con un obstáculo inesperado: las FDP. Creadas en 1983 en el marco del Tratado de Neutralidad del canal de Panamá, su misión fue concebida para defender la vía acuática contra peligros internos, después del año 2000 cuando Estados Unidos retirara su último soldado del país. [...] Según la ley 20 de 1983, las FDP son todopoderosas. En

${ }^{12}$ Mayor Daniel Delgado Diamante, declaraciones grabadas, Panamá, 18 de marzo de 1988. 
gran parte dependen del financiamiento de Estados Unidos. Para superar esta situación de subordinación, las FDP concibieron su propio proyecto: complementar la defensa del canal a partir del año $2000 \mathrm{con}$ la administración del mismo.

La administración del canal les daría autonomia frente a Estados Unidos. Tambiên les daría autonomía frente a la naciónestado panameño. El proyecto concebido por las FDP, que se coloca por encima de los intereses de la nación panameña, choca de frente con el proyecto trasnacional elaborado en Estados Unidos y adoptado por el sector financiero de la burguesía panameña. ${ }^{13}$

Varios meses antes de que Reagan desatara la fase anticipatoria de la invasión final al resolver el bloqueo económico de Panamá y otras medidas agresoras e intervencionistas, el objetivo de destruir a las FDP y el de retener más allá del año 2000 la presencia militar estadunidense en la zona del canal, fue diáfanamente expuesta por Roger Fontaine, un supuesto experto en temas de América Latina. Fontaine fue uno de los redactores del conocido Documento de Santa $\mathrm{Fe},{ }^{14}$ en el que, entre otras cosas, se agredía específicamente al general Omar Torrijos y además se señalaba premonitoriamente:

"Panamá se encuentra bajo el control de un régimen militar de izquierda. [...] El problema es cómo hacerle frente a un

${ }^{13}$ Marco A. Gandásegui, Panamá: crisis política $y$ agresión económica, Centro de Estudios Latinoamericanos Justo Arosamena, Panamá, julio de 1989, pp. 29-30.

14 "A new inter-american policy for the eighties", prepared by the Committee of Santa Fe, New Mexico, for the Council for Inter-American Security, Inc., Washington, D.C., may, 1980. Véase nuestra traducción comentada en $E l$ documento de Santa Fe, Reagan y los derecbos bumanos, Editorial Alpa Corral, México, 1988. asunto bilateral potencialmente peligroso y explosivo. [...] El canal de Panamá tiene un valor estratégico vital para la mayor parte de los países de este hemisferio." El "cómo hacerle frente" según no pocos observadores suspicaces panameños, consistió en que, un año después de editado aquel texto, el avión en que viajaba aquel militar sufrió un misterioso accidente, a resultas del cual murió.

Fontaine era entonces asesor de seguridad nacional para América Latina del presidente Reagan. Ocho años después de emitido aquel texto, el mismo grupo "santafesino" editó otro afín con el título de Documento de Santa Fe II, en el que de nuevo se percibía el dictado de aquel reputado neoderechista, al menos en lo atínente al tema de Panamá, que en vísperas de la elección de George Bush seguia preocupándole. Alli Fontaine fue más lejos y postuló la "expulsión de Noriega" además de "la reforma de las FDP" y una "adecuada defensa realista del canal después del año 2000", objetivo que "deberá incluir la retención, por parte de Estados Unidos, de un número limitado de instalaciones (militares) en Panamá - principalmente la base aérea Howard y la estación naval Rodman-para una adecuada proyecciön de fuerza en el hemisferio occidental". ${ }^{15}$

El mismo Fontaine ya había sido bastante más explícito al encarar ese tema durante el seminario que entre el 6 y el 8 de diciembre de 1987 realizó en

15 "A new inter-american policy for the nineties", prepared by the Committee of Santa Fe, New Mexico, for the Council for Inter-American Security, Inc., Washington, D.C., august, 1988. Véase nuestra traducción comentada, "Santa Fe II: una estrategia para América Latina en la década de 1990", en Tareas, núm. 72, mayo-agosto de 1989 , pp. 3-42; y también en Enriqueta Cabrera (comp.), "respuestas a Santa Fe II", apéndice, El Día en Libros, México, 1989, pp. 189-219.
1

8

5 
Hawai el Consejo de Seguridad Internacional (ISC), una de las tantas organizaciones de la nueva derecha estadunidense caracterizadas como grupos de presión política e ideológica. Su ponencia tenía por título "El canal de Panamá: los temas y el futuro" ${ }^{16}$ y de ella es útil el rescate de los siguientes párrafos ilustrativos:

"Estados Unidos (y sus amigos y aliados) desean un canal de Panamá seguro y eficientemente manejado, que satisfaga todas las necesidades comerciales y militares hasta bien entrada la próxima centuria. Estos intereses tambièn incluyen líneas de comunicaciones seguras a

${ }^{16}$ Roger W. Fontaine, "The Panama canal: the issues and the future", november 19, 1987, 19 pp., mimeo. Véase nuestra traducción del documento, "El canal de Panamá: los temas y el futuro", en Tareas, núm. 69, mayo-agosto de 1988, pp. 83 108. través de la región, así como en las proximidades del canal. Esto significaría que Panamá [nótese que no dice 'el canal'] puede ser aún utilizado en el próximo siglo como una base logística y de aprovisionamiento para ayudar a asegurar los intereses estadunidenses en el resto del hemisferio occidental y de América Central en particular. Idealmente, nuestros intereses pueden incluir un Panamá estable, próspero y preferiblemente democrático.[...]

"Los 10000 soldados del Comando Sur de Estados Unidos actualmente estacionados en Panamá no están per se allí estacionados para la defensa del canal.

"Finalmente, la clave para una intensa cooperación futura es la transformación de las propias Fuerzas de Defensa (FDP). para que estén más en armonía con nuestros valores y preocupaciones (to be more attuned to our values and con-

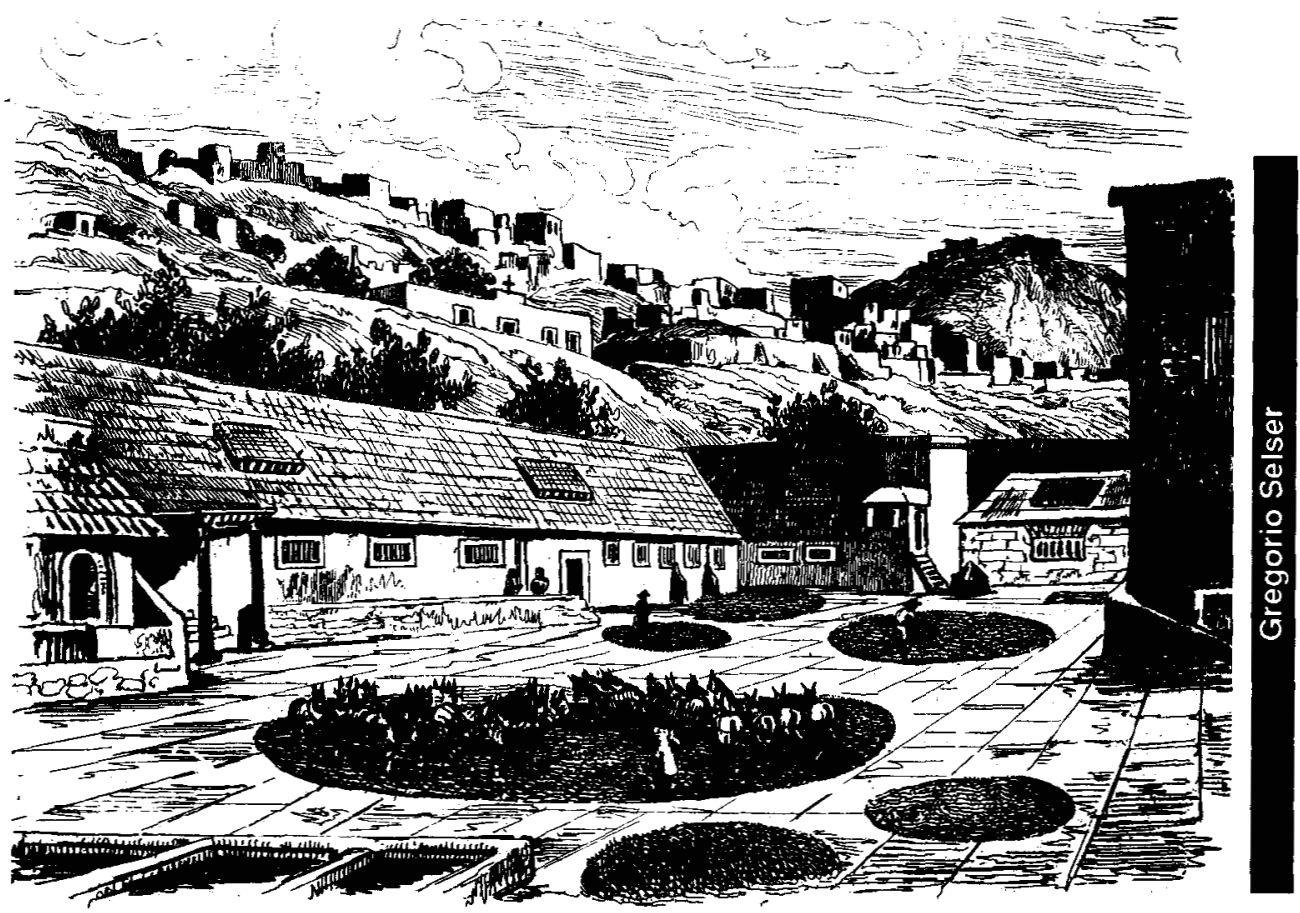


cerns), Estados Unidos tendrá entonces que asumir un papel mucho mayor en su entrenamiento y formación. Esto va mucho más allá de perfeccionar las capacidades profesionales de las FDP. Al igual que en El Salvador, significa cambiar la naturaleza básica del cuerpo de oficiales. [...]

"A algunos planificadores militares, por lo menos en un mundo ideal, les gustaría conservar cierta presencia en Panamá, muy por encima de la base aérea Howard y las instalaciones navales de Rodman. [...] Estados Unidos debería conservar [...] Howard. Está bien ubicada para operaciones logísiticas y proyección de fuerza lforce projection: presencia militar disuasival a lo largo de la región. [...] También coinciden en que una estación naval de reabastecimiento de combustible en Rodman [...] será igualmente de gran ventaja, particu- larmente en los años próximos. [...] Finalmente, tanto Howard como Rodman podrían contribuir mucho a la defensa de las bocas del canal. Y los establecimientos ya instalados y operantes son mucho más fáciles de utilizar que los que tendrían que ser reactivados, incluso a partir de una invitación que formulara el país anfitrión."

Tenemos, pues, aquí, una vez más, reunidos los dos objetivos enunciados, la retención de ciertas bases e instalaciones además del ilegal Comando Sur en la zona del canal, y cambios en "la naturaleza básica del cuerpo de oficiales", una "transformación" para que esté "más en armonía" con los "valores y preocupaciones" de Estados Unidos, algo que teóricamente no tendría que "preocupar" a esa potencia ni a Fontaine puesto que se trataba de la fuerza armada de un país soberano e indepen-

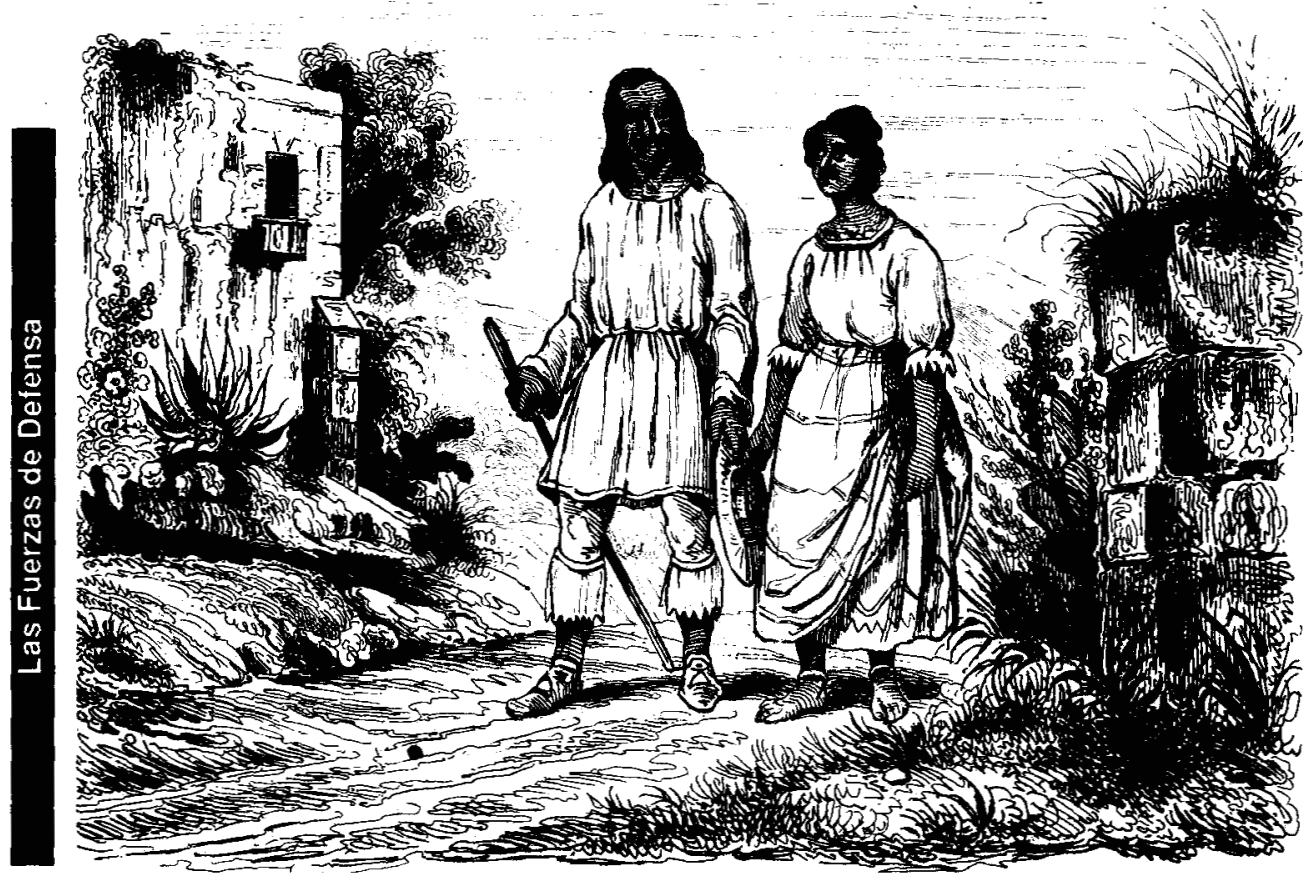


diente. Al menos entonces. Resulta sugestivo que además, Fontaine mencione que deberá ser "el país anfitrión" el que formule "una invitación" a Estados Unidos para que éste se quede en lugar de irse como lo disponen los Tratados TorrijosCarter aún no derogados. Pero como era conocida la decisión de las FDP de ceñirse al cumplimiento estricto de esas convenciones...

Casi a partir del momento de su instalación a horcajadas de los tanques de los invasores, el régimen de Endara y sus voceros proclamaron intermitentemente, aunque con variables formales, que se proponían eliminar la institución armada nacional y reemplazarla con un cuerpo policiaco al que denominaron "fuerza pública". El modelo que diseñaban tenía resonancias históricas. Se parecía bastante a lo que hasta principios de los años cincuenta era llamado "policia de pito y tolete", virtualmente agentes de tránsito munidos de,silbato y macana o porra. Depreciados, mal pagados, obligados a recurrir a pequeñas corruptelas toleradas por las autoridades civiles, eran policías casi-militares-perono-tanto, al servicio de los sectores económico-políticos hegemónicos en turno, sin inquietarlos ni preocuparlos.

Se trataba, al igual que en la vecina república de Costa Rica, de una guardia nacional o guardia civil o guardia rural que ahorraba a las clases dominantes los costos de un ejército profesional al clásico estilo centroamericano y no se involucraba en el control, la supervisión o la investigación de los cuantiosos ilicitos que aquéllas perpetraban según las peores tradiciones heredadas de la España colonial a favor de la Ruta del Tránsito, fundamentalmente el contrabando de todo tipo, la evasión de impuestos, la corrupción administrativa, la represión social y política, el fraude electoral y hasta el narcotráfico en todas sus variables. No resultó así extraño que, en un artículo especial, el presidente costarricense Oscar AriasSánchez, aconsejara a sus "hermanos y hermanas panameños" (en favor de los cuales no había alzadosu voz, en calidad de Premio Nobel de la Paz, contra la indiscriminada matanza de los invasores), la proscripción del ejército nacional "como una institución permanente".

El mensaje de Arias era diáfano:

Todos debemos colaborar con Panamá y su pueblo para superar los desafíos que hoy afronta y [para quel en esta hora de gran confusión y violencia, [...] puedan adoptar históricas decisiones que puedan cambiar el destino del país para siempre. [...] Como representante de una nación que hace más de cuatro décadas abolió el ejército, me tomo la libertad de proponer al pueblo panameño que considere el vivir sin fuerzas armadas.

Desmilitarizar el país implica tomaruna profunda decisión. No es suficiente cambiarle el nombre a las fuerzas armadas. Es necesario cambiar las mentes de los pueblos que hasta ayer lucieron el uniforme militar. Se requiere el valor de proscribir el ejército como institución permanente y decirle sía un futuro en que las armas no sean necesarias, en el que la fuerza de la razón prevalezca sobre la razón de la fuerza. ${ }^{17}$

Escrito para un público de Estados Unidos, que figura entre los más ignorantes en materia de América Latina, el texto de Arias contenía sutiles falsificaciones. Costa Rica le había cambiado el nombre a su ejército por el de guardias, por ejemplo, pero su número, pequeño

${ }^{17}$ Oscar Arias Sánchez, "Panama, without an army", The New,York Times, 9 de enero de 1990, p. 15. 
hasta los años setenta, se había incrementado desde 1986 en adelante -durante la presidencia de Luis Alberto Monge- hasta alcanzar con el propio Arias la cifra respetable de 23185 efectivos en 1989, sumadas sus distintas dependencias y especialidades, es decir, algunos millares más de los que integraban las Fuerzas de Defensa de Panamá al momento de la invasión armada de Estados Unidos; ${ }^{18}$ esta intervención bélica mostraba que, contra la beatífica exhortación de Arias, el presidente Bush había preferido, como tantos otros predecesores suyos en Washington, la razón de la fuerza a la fuerza de la razón.

Entre otros argumentos de discutible y sinuosa factura, el presidente Arias añadía los siguientes:

No faltarả quien afirme que es necesario un ejército para salvaguardar el canal. Pregunto: en un mundoen que los enemigos de ayer se reúnen para derribar muros, en un mundo en el que la guerra fría da paso a la cooperación y a la solidaridad, ¿no es más invencible la fuerza moral de una nación que construye la paz, que las armas que sólo han servido para burlar la voluntad de los pueblos manifestada en lasurnas, comoes la triste historia de tantas naciones de la tierra? De todas maneras, pueden convenirse varios acuerdos prácticos -regionales o internacionales- que garanticen la seguridad del canal. ${ }^{19}$

La propuesta, de apariencia tan noble como angelical, omitía deliberadamente los términos verdaderos de las ecuacio-

${ }^{18}$ Cfr. el detalle completo en Presupuesto ordinario y extraordinario de la república, San José, 1989; y en Situación de los derechos bumanos en Costa Rica, Comisión Costarricense de los Derechos Humanos, San José, 1989, en los que una vez más queda expuesto sin disfraces el mito de "país sin ejército". Lo tiene y a la medida de sus necesidades, aunque no lleve ese nombre.

${ }^{19}$ Oscar Arias Sánchez, op. cit., p. 19. nes. El nuevo mundo idílico al que se refería era el de las potencias mayores del orbe, las del primer mundo y el segundo mundo también descrito como Norte-Norte, pero no así el de la relación desigual del mundo Norte-Sur; y, en tal marco de referencia, Arias parecía pedirle a Panamá lo que en verdad debía demandarle a Estados Unidos, y también con relación a Nicaragua, El Salvador, Angola, Cuba y otros tristes ejemplos. ¿Era lo mismo el grado de reverencia al respeto mutuo entre Washington y Moscú, basado en la perspectiva a pocalíptica de un común nivel de destrucción asegurada en caso de conflicto bélico, que el total desprecio mostrado por Washington por los países débiles e inermes del Tercer Mundo, o que su desdén tradicional por las normas del derecho internacional cuando de pequeñas naciones se trate?

Y en lo atinente a la seguridad del canal, ino era precisamente el meollo de toda la operación desestabilizadora contra el gobierno panameño primero, y de la agresión armada contra su pueblo después, la voluntad de los gobiernos de Ronald Reagan y George Bush de incumplir los Tratados Torrijos-Carter de 1977 , que entre sus numerosas cláusulas prevén precisamente la pacífica custodia de la seguridad y neutralidad de esa vía acuática, que a partir del primer día del año 2000 debe quedar a cargo de la república de Panamá y de su ejército nacional?

Cuando aún se luchaba contra las tropas invasoras, el Herald de Miami auguraba:

Algunos viejos miembros de las Fuerzas de Defensa de Noriega están aún resistiendo la ocupación estadunidense y algunas preguntas esperan respuestas acerca de la nueva Fuerza Pública que está 


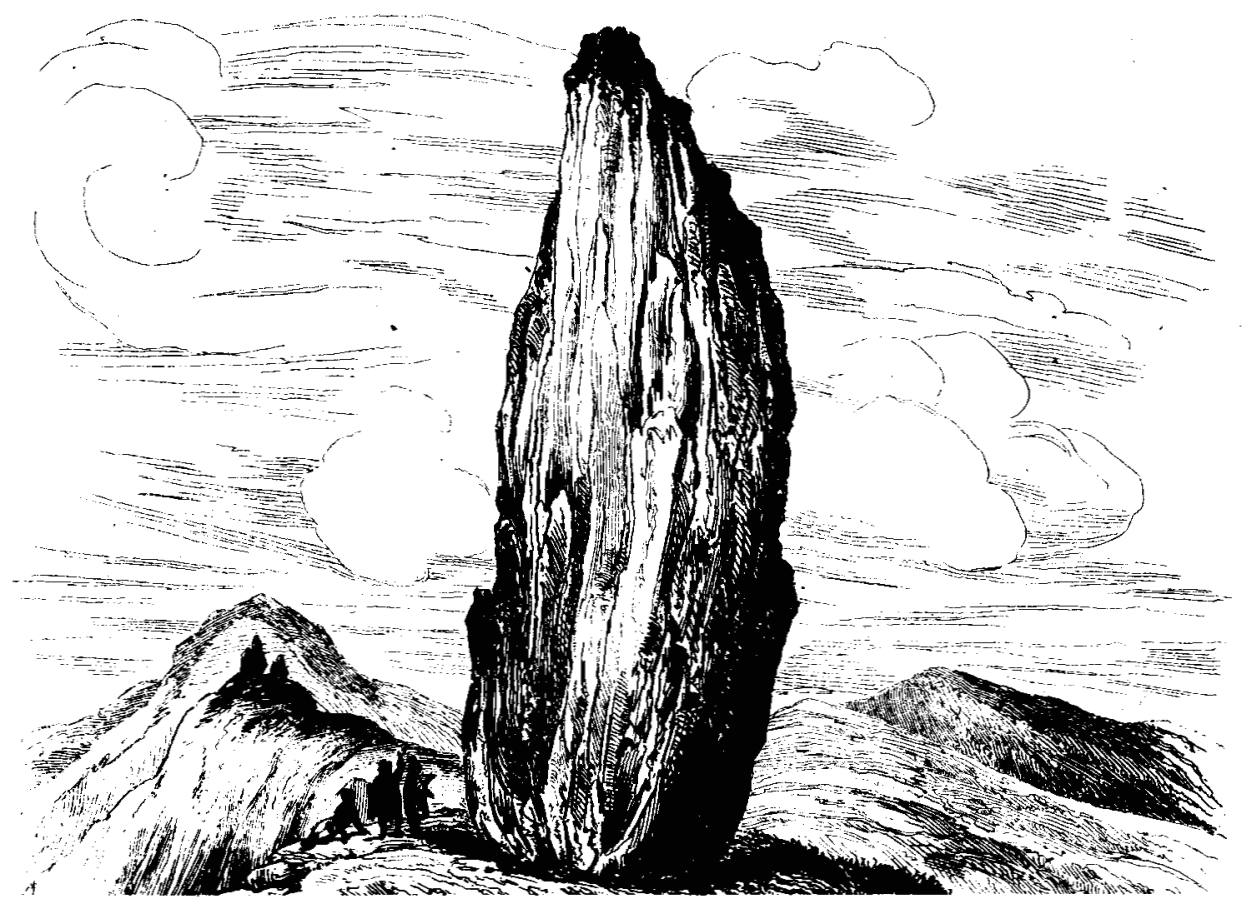

siendo erigida, casi literalmente, sobre las ruinas de lo antiguo. El nuevo gobiemo, en estrecha unión con las autoridades militares de Estados Unidos, está construyendo una nueva fuerza que será pequeña, menos opulenta y menos poderosa que las FDP [...] la que será ayudada por las tropas norteamericanas a establecer el orden como un cuerpo policial.

[...] Después de una conferencia de prensa, Ricardo Arias se dirigió en un carro blindado norteamericano hacia el cuartel de la policía de tránsito. Allí lo recibió Al Cornell, coronel del ejército norteamericano que es su oficial de enlace; Cornell, que hasta hace tres meses fue el agregado militar de Estados Unidos en Panamá, fue llevado de vuelta la semana pasada para que aportara su experiencia al servicio de la complicada labor de reestructurar el ejército nativo.

Arias Calderón y el coronel Cornell se sentaron y en un cuaderno de notas borronearon nombres. Al concluir, dijo Cor-

nell: "Desde ahora ninguno de estos militares harán las cosas por su cuenta ni actuarán independientemente, porque de lo contrario, muy pronto ustedes tendrán otro Noriega". ${ }^{20}$

El 12 de enero de 1990 , una fotografía a tres columnas en el Times, mostraba al hombre que había prestado juramento en la base militar norteamericana de Fort Clayton cumpliendo una simbólica ceremonia que el pie de grabado describía así: "El cuartel general de Noriega será pronto historia. El presidente panameño Guillermo Endara, utiliza una maza para derribar una pared de lo que resta del cuartel general de Noriega en la ciudad de Panamá. La demolición formal se inicia hoy." "No era, claro está, el cuartel gene-

${ }^{20}$ Sam Dillon, "Panama military reforms as rapidly as it tumbled apart", The Miami Herald, 27 de diciembre de 1989, p. 1.

21 "Noriega headquarters will soon be history", 
ral de aquel militar, sino de las FDP, del ejército nacional. Un editorial del mismo diario, de ese día, con el título de "Panamá no necesita ejército", luego de comentar la propuesta hecha por el gobernante costarricense Oscar Arias de abolir las FDP, "idea que tiene sentido", añadía estos párrafos finales:

"La más urgente necesidad del presidente Guillermo Endara es formar una nueva fuerza policial panameña leal a su gobierno civil, para hacer posible una pronta retirada de las tropas de ocupación de Estados Unidos. Entonces él y Panamá harán bien en considerar el modelo de Costa Rica, su vecino del norte: ninguna clase de ejército." 22

Una conocida académiça panameña, la demôgrafa Carmen Miró, directora del Instituto de Estudios Nacionales de la Universidad de Panamá e integrante de la Coordinadora Nacional de Apoyo y Solidaridad creada a raíz de la invasión, reafirmó la naturaleza verdadera de la operación "Just Cause":

"Nosotros pensamos que Noriega es sơlo el pretexto para justificar la invasión de Panamá. Pero las características brutales de esa invasión nos hacen pensar que el objetivo era, en primer lugar, destruir las Fuerzas de Defensa. Ese organismo fue creado, armado y financiado por Estados Unidos. Durante años funcionó aquí la malhadada Escuela de las Américas, donde entrenaban a oficiales de alto nivel de los ejércitos latinoamericanos; pero, por una razón que no está clara para nosotros, se produce una ruptura. El propósito fundamental es entonces destruir todo eso que

leyenda de grabado, The New York Times, 12 de enero de 1990 , p. 8.

22 "Panama needs no army", editorial de The New York Times, 12 de enero de 1990, p. 14. se les había escapado de control.

"La prueba más evidente es que destruyen los cuarteles; no tratan de apresar a los miembros de las FDP. En primer lugar lanzan ataques masivos, potentes, de artillería, destruyendo todos los edificios. A la situación de crisis a la que se había llevado al país mediante las sanciones económicas, hay que agregar otra agresión, que es la de permitir el pillaje. Si una fuerza policial es destruida y no se le sustituye con ninguna otra no hace falta ser muy inteligente para entender que se van a producir saqueos.

"Ellos ya declararon que harăn cumplir los Tratados Torrijos-Carter que obligan a los Estados Unidos a entregar el canal el 31 de diciembre de 1999. Con certeza habrá exigencias de algún tipo de Estados Unidos y debemos estar muy alertas para evitar un nuevo cercenamiento de la soberanía panameña, principalmente por la permanencia de bases norteamericanas aquí después de esa fecha. Su principal interés es continuar su presencia militar en Panamá más allá del año 2000 . Hoy existen condiciones que lo hacen más fácil. Será nuevamente el ejército norteamericano el que organice a la fuerza pública." 23

La comandancia de las FDP estaba ubicada junto al barrio popular de El Chorrillo, prácticamente devastados ambos por el bombardeo aéreo y dela artillería estadunidenses en las horas siguientes a la invasión. Al dar su simbólico mazazo sobre las ruinas del edificio ya parcialmente destruido, Endara declaró que la demolición total concluiría en 40 días. Añadió: "Este país no necesita ejército sino sólo unas pocas fuerzas especiales que cuiden el orden público. Sobre las cenizas del militarismo se constituirá el

${ }^{23}$ Gilberto López, entrevista a Carmen Miró, "Noriega fue sólo el pretexto para justificar la invasión", Revista Universidad, 12 de enero de 1990, San José, p. 19.

\section{1}

9 
mejor mode-lo de la reconstrucción del país."

El 11 de febrero de 1990, el régimen impuesto por las tropas de ocupación derogaba, por decreto, la ley 20 de 1983 -que regulaba el funcionamiento de las FDP- y creaba oficialmente la Fuerza Pública Panameña (FPP), ubicándose al presidente de la república como su "jefe supremo". La resolución establecía que hasta tanto no fuese aprobada su ley orgánica, la FPP "estará integrada por la Policía Nacional, el Servicio Aéreo Nacionaly el Servicio Marítimo Nacional, con mandos y escalas separados, bajo la autoridad y dependencia del ejecutivo por conducto directo del ministro de Gobierno y Justicia". El decreto creaba además un cuerpo asesor del presidente, denominado Consejo de Seguridad Pública y Defensa Nacional, integrado por los ministros de Gobierno y Justicia, Relaciones Exteriores y Planificación y Política Económica: "La Fuerza Pública depende directamente del órgano ejecutivo y su actuación estará sujeta a la Constitución y a las leyes, con pleno respeto a los derechos humanos, para resguardo y apoyo de las instituciones democráticas."

Los miembros de la nueva FPP podrian participar en políticas partidistas "únicamente para emitir el voto", en tanto que los oficiales y jefes "no ejercerán coacción de ninguna índole sobre los miembros bajo su mando", ni podrán participar en actividades políticas de ninguna clase mientras estén en servicio activo, ni formular declaraciones de carácter partidista. Será el presidente, con la participación del ministro respectivo, quien nombre o separe a los jefes, oficiales y miembros de la FPP y confiera ascensos de acuerdo con el escalafón. También ambos podrán organizar unidades especiales en la Policía Nacional para la vigi- lancia fronteriza, la protección de la integridad del territorio nacional y del canal de Panamá.

Los efectivos del nuevo organismo no deberán exceder de un porcentaje -aún no especificado- de la población, pero en caso de guerra o de grave perturbación del orden público el ejecutivo podrá decretar temporalmente su incremento, "sujeto a la aprobación respectiva del órganolegislativo dentro del término de 30 días a partir de la adopción de la medida". Se reconoce la antigüedad de quienes formaban parte de las disueltas FDP y que se hubieran incorporado a las FPP. El ministro Ricardo Arias Calderón declaró que, de esta manera "se ha pro-cedido a darle la primera forma legal a la desmilitarización de Panamá". 24

La oligarquía obtenía así su ansiado objetivo de décadas, que se remontaba a los tiempos en que el líderultraderechista y conservador Arnulfo Arias Ma-drid ansiaba hacer de la fuerza armada nacional una "policía de pito y tolete" según la caracterización histórica a la que la habían reducido desde principios de siglo. Desde México, el principal periódico libero-conservador iba a comentar:

Una nación sin ejército corre el riesgo de ver en peligro su soberanía, y en el caso de Panamá, concretamente, la intervención de Estados Unidos, decisiva para la línea política actual alli, es un hecho paradójicamente opuesto a la autonomía de un país [...] El ejército de Panamá es abolido y las tropas estadunidenses que ocupan esa nación todavía permanecen alli. [...] Actualmente Estados Unidos es el país que tiene en Panamá innegable y profunda injerencia. Mañana podria ser otra nación. ${ }^{25}$

${ }^{24}$ "Crean una nueva fuerza pública en Panamán", cable de ACAN-EFE, El Nuevo Diario, 12 de febrero de 1990, Managua, p. 2.

25 "Panamá sin ejército", editorial de Excélsior, 12 de febrero de 1990, México, p. 6. 